\title{
Development of Pavement Roughness Prediction Model for National Highways in Sri Lanka
}

\author{
R.M.K. Sandamal and H.R. Pasindu
}

\begin{abstract}
National highways play a pivotal role in the economic development of a country. Maintaining the road network in optimal condition is imperative to ensure in this regard. An accurate pavement performance prediction model is an important tool for pavement maintenance management to optimize the life cycle cost of maintenance and rehabilitation strategies. At present, there is limited research carried out to develop a pavement performance model for Sri Lanka. In this study, pavement roughness progression of national highways in the long-term performance was analysed to develop an accurate roughness deterioration model. The International Roughness Index (IRI) is a global parameter to measure the ride comfort and the unevenness of pavement. Axle loading and the ageing effect result in functional and structural failure of a pavement which manifests into deterioration of pavement condition. The contribution of different distresses on IRI progression is investigated using the HDM-4 deterioration model. Furthermore, the relationship between IRI progression with pavement age and traffic volume is developed and compared with such models developed in other countries to identify if there exist major differences. The findings of the study could be used in the maintenance management decision making to forecast pavement condition and make future plans.
\end{abstract}

Keywords: International Roughness Index, National Highway, Calibration

\section{Introduction}

In Sri Lanka, there are 12, $438 \mathrm{kms}$ of national highways (class A, B \& E) in different environments and terrain conditions [1]. The national road network in the Western Province has the maximum road density among them as $0.46 \mathrm{~km} / \mathrm{km}^{2}$, whereas the total national road density of Sri Lanka is $0.19 \mathrm{~km} / \mathrm{km}^{2}$ [2,3]. Understanding the condition of these roads as well as the available tools to forecast the future condition of the road network is an important input in road maintenance decision making. These 'performance models' are a vital component in any pavement management system used by highway authorities. Pavement performance can be evaluated using various attributes such as distress condition, roughness, skid resistance, etc.

Road roughness is globally accepted as a parameter to measure the pavement condition, especially for network-level condition assessment which reflects the riding quality. According to the Federal Highway Administration (FHWA), pavement roughness is considered the single most important factor affecting the riding quality [4]. Moreover, roughness also indirectly represents the presence of major distress on pavement surfaces such as ravelling, pothole, cracking, etc. [5]. The increase of road roughness tends to increase fuel consumption and vehicle repair cost [6]. An accurate pavement roughness deterioration model can be used to overcome the above-mentioned issues by predicting functional performance in pavement service life. Different countries have developed pavement performance models to predict roughness deterioration with pavement age, axle loading, etc. [7]-[9]. However, the adaptability of these models under different weather and traffic conditions remains uncertain. Moreover, there is no real field data analysis conducted in Sri Lanka to predict roughness deterioration. The HDM- 4 model commonly adopted in Sri Lanka should also be calibrated to incorporate local conditions.

The objective of this research is to develop a pavement performance model to evaluate the variation of roughness for the relevant contributing factors such as traffic volume, pavement age and initial construction quality. Further, a methodology to calibrate the roughness deterioration model in HDM-4 using the developed deterioration curves is also presented in the study.

Eng. R.M.K. Sandamal, AMIE (SL), B.Sc. Eng. (Hons)

(Moratuwa), Research Assistant, Department of Civil

Engineering, University of Moratuwa.

Email:198046r@uom.lk

ORCID ID: $h$ ttp://orcid.org/0000-0002-7451-4667

Dr. H.R. Pasindu, MIE (SL), B.Sc. Eng. (Hons)

(Moratuwa), PhD (NUS,) Senior Lecturer, Department of

Civil Engineering, University of Moratuwa, Sri Lanka.

Email:pasindu@uom.lk

ORCID ID: http://orcid.org/0000-0002-2612-3143 


\section{Review of Pavement Roughness Prediction Models}

\subsection{Factors Affecting the Roughness Progression}

There are different types of factors affecting roughness progression on roads such as traffic level, construction defects, design factors, environmental factors, etc. Among them, traffic loading is an imperative factor in estimating roughness deterioration prediction models. Increase in volume of heavy trucks increases the static and dynamic loading, leading to increase in pavement deterioration $[10,11]$. Moreover, the study conducted by Alaswadkoet al. [12], used Average Annual Daily Traffic (AADT) and the number of commercial vehicles as traffic factors in the model development.

The design factors have a significant effect on the initial roughness and long-term performance of the pavement. Hot Mix Asphalt (HMA) thickness can be considered as the main design factor which affects the initial roughness, and when the layer thickness is increased the initial roughness is decreased $[13,14]$. Furthermore, HMA mix classification and type of base layer are the other major design factors that influence the performance. The results from Haifang [13] show that rural roads are smoother than urban roads because rural road construction has fewer interruptions and lesser utilities.

Moreover, in the long-term performance, it can be seen that environmental factors affect the deterioration rate. The climate characteristics of temperature and air humidity may increase pavement deterioration since temperature increases will increase the oxidation rate of bituminous binder in asphalt layers by decreasing the rigidness [15]. Further precipitation, moisture deficit, evapotranspiration and soil water storage influence roughness $[13,16]$. The subgrade soil type has a direct relationship to the pavement deterioration rate. From the results of the study conducted by Jameson [17] and Mann [18], it could be seen that, when the subgrade includes expansive material, deterioration is accelerated under seasonal moisture variations. Moreover, Alaswadko [12] refers to soil reactivity $(54 \%)$ as the second most important factor after high traffic loads (62\%) influencing pavement roughness progression. In addition to the above-mentioned factors, drainage and terrain type can be considered as the other factors contributing to the roughness progression.

\subsection{Roughness Prediction Models}

Pavement roughness can be measured by using different indices such as Ride Number (RN), International Roughness Index (IRI), Half-car Roughness Index (HRI), Mays Ride Meter (MRM), Quarter-car Index (QI) and Present Serviceability Index (PSI) [19]. Among them, IRI is globally accepted as a suitable parameter to measure the pavement roughness. The IRI reported in unit $\mathrm{m} / \mathrm{km}$ was developed by the International Road Roughness Experiment held in Brazil in 1982 and adopted as the unit to define roughness. IRI is calculated as the accumulation of the simulated motion between the sprung and unsprung masses in the quarter-car model, divided by the length as shown in equation 1 [20].

$I R I=\int_{0}^{T} \frac{\left|\dot{z}_{u}-\dot{z}_{S}\right|}{L} d t$

Where, $\dot{z}_{u}$ is the vertical velocity of the unsprung mass (axle), $\dot{z}_{s}$ is the vertical velocity of the sprung mass (vehicle body), $L$ is the length of the measure and $T$ is the time duration.

The developed prediction models can be classified into two categories, deterministic and probabilistic models [21]. The deterministic models are either empirical of MechanisticEmpirical (M-E), consisting of the primary response, structural performance, functional performance and damage models [22]. The probabilistic models include Markov Chain, Bayesian regression and survivor curves $[21,23]$. In the probabilistic models the current pavement condition is known in probabilistic form. Then using the Markov Chain models or survival curves future pavement condition can be predicted.

Empirical models are developed by implying regression analysis which generates relationships between parameters such as pavement age, cumulative traffic load, climate condition, pavement aging effect, etc. Traffic characteristics such as Cumulative Standard Axle Load (CSAL), Average Daily Traffic (ADT), percentage of heavy vehicles ( $\mathrm{HV} \%$ ) and structural parameters (such as the structural number (SN) and pavement thickness) are used as primary independent variables. George [24], developed the IRI 
prediction model for the asphalt concrete overlay roads and concluded a robust coefficient of determination $\left(\mathrm{R}^{2}\right)$ of 0.53 , based on 1143 observations and described in equation 2 .

$I R I=\left(3.095+A g e^{0.3571}\left(1+C E S A L^{0.3054}\right)\right)$

\section{TOPTHK-0.3235}

Where, TOPTHK is the thickness of the most recent overlay, CESAL is the cumulative 18-kip equivalent standard axle load applied to the pavement and Age is the age of pavement since construction.

M-E models are a combination of mechanistic and empirical parameters that are incorporated into the prediction model. In addition to the empirical parameters, these models include material properties which are used to evaluate damage or performance. In the analysis, parameters are estimated by the non-linear joint estimation method [25]. The study performed by Prozzi \& Madnat [26] developed a M-E model by joint estimating the AASHO road test and Minnesota Road (MnRoad) data, as presented in equation 3 .

$r_{i t}=\theta_{1} e^{\theta 2} \cdot H 1 i+\sum_{l=0, t-1}\left(\theta_{3} \cdot E A T_{i}^{\theta 9} \cdot e^{\theta 10 \cdot G 1} \cdot N_{i l}^{\theta 11}\right.$. $\left.\Delta N_{i, l+1}\right)$

Where, $r_{i t}$ is the IRI in the $\mathrm{i}^{\text {th }}$ year in unit $\mathrm{m} / \mathrm{km}$, EAT is the equivalent asphalt thickness, $H_{j}$ is the layer thickness, $G$ is the frost gradient and $\theta_{j}$ is the parameters to be estimated.

The pavement deterioration process shows stochastic characteristics due to uncertainty arising due to the inability to quantify some factors. The use of probabilistic models to tackle stochastic characteristics increases the accuracy significantly [27]. Markov Chain model, which is a discrete-time stochastic process, will determine the pavement condition $X_{t+1}$ at time $t+1$ based on the $X_{t}$ at a previous time $t$ as shown in equation 4 .

$P\left(X_{t+1}=j \mid X_{t}=i\right)$

Where, $P$ is the probability of the condition at time $t+1$ being $j$, given that the condition at time $t$ was $i$.

A summary of developed roughness prediction models worldwide is shown in Table 1.
2.2 IRI Thresholds for Flexible Pavements

The IRI summarises the roughness qualities that impact vehicle speed and operating cost while providing user comfort indications. Figure 1 shows the IRI ranges represented by different road types and respective comfortable speeds [28]. Moreover, it is shown that for paved roads, IRI is varying from $1.5 \mathrm{~m} / \mathrm{km}$ to $10 \mathrm{~m} / \mathrm{km}$ during the pavement service life. Further, it shows the increase of pavement roughness will reduce the speed drastically.

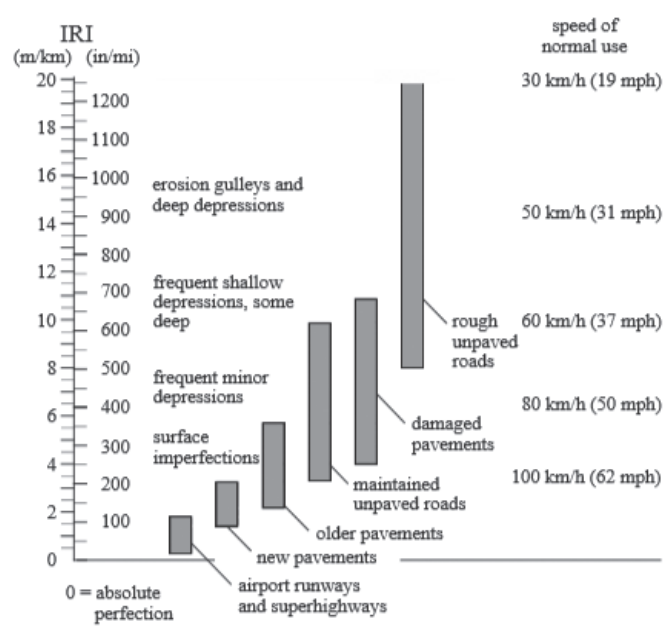

Figure 1 - IRI Ranges for Different Road Types of with Comfortable Speed Limits [29]

The threshold values are a function of road surface type, road functional category, speed limit, segment length, AADT and construction type [29]. However, some standards in some countries have defined different IRI threshold values concerning road type for acceptance of new roads and for in-service roads which are shown in Table 2. The maintenance intervention IRI intends that when road reaches to that IRI value, a maintenance strategy should be applied.

The roughness deterioration rate varies with the climate condition, traffic density and road type, as shown in Table 1. The study done by Paterson [30] shows that the deterioration rate is $0.16 \mathrm{~m} / \mathrm{km}$ per annum up to 13 years, accelerated to $1.75 \mathrm{~m} / \mathrm{km}$ thereafter. Moreover, results from Soncim [31] state that annual roughness progression varies from 0.15-0.25 $\mathrm{m} / \mathrm{km}$ depending on the traffic volume and climate. Furthermore, the maximum annual increase of pavement roughness can be raised to $0.40 \mathrm{~m} / \mathrm{km}$ when the affecting factors reach to their maximum values [30]. 
Table 1 - Summary of the Roughness Prediction Models

\begin{tabular}{|c|c|c|c|}
\hline Reference & $\begin{array}{l}\text { Type of } \\
\text { Model }\end{array}$ & Factors Used & Key Findings \\
\hline George [24] & Empirical & $\begin{array}{l}\text { AC overlay thickness, } \\
\text { (TOPTHK), CESAL, } \\
\text { Pavement age }\end{array}$ & $\begin{array}{l}\text { Regression equation: } I R I=\left(3.095+A g e^{0.3571}\right. \\
\left.\qquad\left(1+C E S A L^{0.3054}\right)\right) T O P T H K^{-0.3235} \\
\text { Pavement age is the most significant predictor of } \\
\text { deterioration. } \\
\text { Power models found to be the best representation. }\end{array}$ \\
\hline $\begin{array}{l}\text { Prozzi \& } \\
\text { Madnat [26] }\end{array}$ & $\begin{array}{l}\text { Mechanistic- } \\
\text { Empirical }\end{array}$ & $\begin{array}{l}\text { Equivalent asphalt } \\
\text { thickness }(E A T) \text {, Layer } \\
\text { thickness }(H) \text {, frost } \\
\text { gradient }(G)\end{array}$ & $\begin{array}{l}\text { Model: } r_{i t}=\theta_{1} e^{\theta 2 . H 1 i}+\sum_{l=0, t-1}\left(\theta_{3} . E A T_{i}^{\theta 9} \cdot e^{\theta 10 . G 1} \cdot N_{i l} \theta 11 .\right. \\
\left.\qquad \Delta N_{i, l+1}\right) \\
\text { Two IRI deterioration stages found as linear and non- } \\
\text { linear by the joint estimating }\end{array}$ \\
\hline $\begin{array}{l}\text { Paterson } \\
\quad[30]\end{array}$ & Empirical & $\begin{array}{l}\text { Structural Number } \\
(S N C), E S A L, \\
\text { pavement age, } \\
\text { Wearing course type }\end{array}$ & 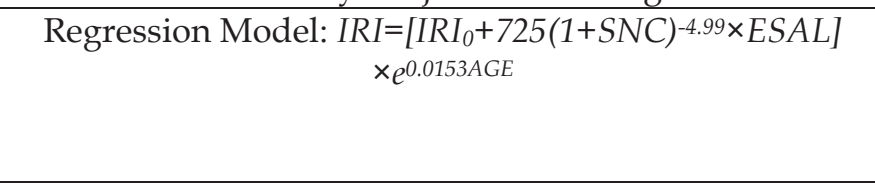 \\
\hline $\begin{array}{l}\text { Soncim et al. } \\
\qquad[31]\end{array}$ & Probabilistic & $\begin{array}{l}\text { Traffic density, } \\
\text { climate, Initial IRI (set } \\
\text { between } 1.5 \text { to } 2.0 \\
\mathrm{~m} / \mathrm{km})\end{array}$ & $\begin{array}{l}\text { Probability Matrix: } P_{i j}(t)=\sum_{k=0, m} P_{i k}(v) \cdot P_{j k}(t-v) \\
\text { Roads located in rainy regions with higher traffic } \\
\text { density present an accelerated deterioration rate } \\
\text { After IRI } 6 \mathrm{~m} / \mathrm{km} \text { reached, deterioration rate increased }\end{array}$ \\
\hline $\begin{array}{l}\text { ARA, Inc. } \\
\quad[32]\end{array}$ & $\begin{array}{l}\text { Mechanistic- } \\
\text { Empirical }\end{array}$ & $\begin{array}{l}\text { Pavement age, fatigue } \\
\text { cracking }(F C)_{T}, \\
\text { transverse cracks } \\
\left(T C_{S}\right)_{H}, \text { Patches }(P)_{H}, \\
\text { Freezing Index }(F I) \\
\end{array}$ & $\begin{array}{l}\text { Model: Bituminous treated base } \\
I R I=I R I_{0}+0.0099947(\text { age })+0.0005183(F I)+0.00235(F C)_{T}+18 . \\
36\left\{1 /\left(T C_{s}\right)_{H}\right\}+0.9694(P)_{H}\end{array}$ \\
\hline $\begin{array}{l}\text { Albuquerqu } \\
\text { \& Núñez } \\
\text { [33] }\end{array}$ & Empirical & $\begin{array}{l}\text { Modified Structural } \\
\text { Number }(S), \text { ESAL } \\
(N), \text { Climate }(C)\end{array}$ & $\begin{array}{l}I R I_{(H M A)}=-173.4+e(5.177+0.001 * C-0.002 * S+0.005 * N) \\
\text { To reach IRI intervention IRI of } 3.5 \mathrm{~m} / \mathrm{km} \text { this model } \\
\text { would take } 9 \text { years. }\end{array}$ \\
\hline Li et al. [34] & Probabilistic & $\begin{array}{l}\text { Initial probability }\left(P_{0}\right) \\
\text { Transition probability } \\
\text { matrix }(T P M)(p), \text { Duty } \\
\quad \text { cycle }(i)\end{array}$ & $\begin{array}{c}\text { Probability Matrix: } P_{i}=P_{o}(P)^{i} \\
\text { Sensitivities of the TPMs to traffic growth rate, } \\
\text { subgrade deflection, and pavement thickness are } \\
\text { significant }\end{array}$ \\
\hline
\end{tabular}

Table 2 - Summary of IRI Limits for New and In-Service National Roads

\begin{tabular}{|c|c|c|c|}
\hline \multirow{2}{*}{ Country } & \multirow{2}{*}{ Road Type } & \multicolumn{2}{|c|}{ IRI Limit Specification (m/km) } \\
\hline & & New Roads & Maintenance Intervention \\
\hline $\begin{array}{l}\text { Missouri, USA } \\
\text { [29] }\end{array}$ & National highways & 1.26 & 2.76 \\
\hline \multirow[b]{2}{*}{ Australia [35] } & Freeways & 1.6 & 3.5 \\
\hline & Main roads $(100 \mathrm{~km} / \mathrm{h})$ & 1.9 & $\begin{array}{l}3.5(\text { speed } 100 \mathrm{~km} / \mathrm{h}) \\
5.3(\text { speed }<80 \mathrm{~km} / \mathrm{h})\end{array}$ \\
\hline \multirow{2}{*}{$\begin{array}{l}\text { Czech Republic } \\
\text { [36] }\end{array}$} & Speed $>50 \mathrm{~km} / \mathrm{h}$ & 1.9 & 4.3 \\
\hline & Speed $<50 \mathrm{~km} / \mathrm{h}$ & 3.0 & 6.3 \\
\hline \multirow{3}{*}{ Russia [37] } & Highways and first class roads & 2.2 & 4.2 \\
\hline & Second and third class roads & 2.2 & 4.6 \\
\hline & Fourth and fifth class roads & 2.6 & 7.7 \\
\hline \multirow{2}{*}{ Norway [38] } & Highways and primary roads & $\begin{array}{c}2(\mathrm{AADT} \geq 3000) \\
2.5(\mathrm{AADT}<3000)\end{array}$ & \multirow{2}{*}{$\begin{array}{c}3.5(\mathrm{AADT}>10,000), 4(\mathrm{AADT} \\
5,000-10,000), 4.5(\mathrm{AADT} 1,500- \\
5000), 5(\mathrm{AADT}<1,500)\end{array}$} \\
\hline & Other roads & $\begin{array}{c}2.5(\mathrm{AADT} \geq 3000) \\
3(\mathrm{AADT}<3000)\end{array}$ & \\
\hline Philippine [39] & National primary roads & 3 & - \\
\hline \multirow[b]{2}{*}{$\begin{array}{c}\text { New Zealand } \\
{[40]}\end{array}$} & Highway & - & 3.82 \\
\hline & Primary roads & - & $\begin{array}{l}4.2(\mathrm{AADT}>10,000), 4.58(\mathrm{AADT} \\
4,000-10,000), 4.96(\mathrm{AADT}<4,000)\end{array}$ \\
\hline
\end{tabular}


Terminal IRI values for acceptance of new AC pavements and maintenance limits are different from country to country depending on the road type and traffic density as illustrated in Table 2. However, the initial IRI value for new roads, especially for national or primary roads, the limit can be established as $2.5 \mathrm{~m} / \mathrm{km}$ based on the values referred to in Table 2. Moreover, it is seen that for in-service roads the maintenance intervention IRI value can be established as $4 \mathrm{~m} / \mathrm{km}$, since most of the countries have maintained that limit.

In Sri Lankan practice, intervention criteria for maintenance of flexible pavement depend on two factors, roughness and AADT. Road Development Authority (RDA), Sri Lanka, has proposed [41] the IRI trigger values for periodic maintenance activities to depend on AADT for national roads which is shown in Table 3 . Moreover, a study conducted by Gnanasekaran [42], using 6 national road stretches, shows that the average initial IRI (within 18 months after rehabilitation) is less than $3.6 \mathrm{~m} / \mathrm{km}$ in all roads and 95 percentile of initial IRI varying in the range of 2.32 to $4.08 \mathrm{~m} / \mathrm{km}$.

Table 3 - Road Maintenance IRI Intervention for National Roads, Sri Lanka [41]

\begin{tabular}{|c|c|c|}
\hline \multirow{2}{*}{ Road Type } & $\begin{array}{c}\text { AADT } \\
\text { Range } \\
\text { (veh/day) }\end{array}$ & $\begin{array}{c}\text { IRI } \\
\text { Intervention } \\
\text { (m/km) }\end{array}$ \\
\hline \multirow{3}{*}{ Class A\&B } & $<5,000$ & 3.5 \\
\cline { 2 - 3 } & $5,000-20,000$ & 3.0 \\
\cline { 2 - 3 } Expressway & $>20,000$ & 2.5 \\
\hline
\end{tabular}

\section{Data Collection}

Thirty-one different road sections in the Western Province national road network, Sri Lanka, with different terrain conditions and traffic volumes, have been selected for the study. Pavement history details in this study include the time of recent rehabilitation and lane geometry. This information was collected from RDA, Sri Lanka and official web pages of leading road construction contractors. In this study, selected roads have a maximum pavement age of 16.5 years since the rehabilitation/construction.

Roughness data for different periods were collected from RDA which were measured by using the laser profilometer in Hawkeye 2000 modules installed onto Multi-Function Network Survey Vehicle (MFNSV) which is
Class-I measuring equipment [43]. Moreover, the current condition of the pavement is measured using the bump integrator which is a Class-III response type measuring equipment [44]. The roughness of the selected road segments was in the whole range of IRI for flexible pavements. The minimum length was limited to $1 \mathrm{~km}$ in the selected roads.

The traffic data was collected from the Transportation Engineering Division of the Department of Civil Engineering, University of Moratuwa and RDA, Sri Lanka. The summary of the collected data for the study is shown in Table 4.

Table 4 - Summary of the Data Collection

\begin{tabular}{|c|c|}
\hline Description & Value \\
\hline Number of roads & 31 \\
\hline Number of data(N) & 221 \\
\hline IRI range & $1.5 \mathrm{~m} / \mathrm{km}-9.1 \mathrm{~m} / \mathrm{km}$ \\
\hline Pavement age & Up to 16.5 years \\
\hline ADT range & 9,000 vehicle $/$ day - \\
115,000 vehicle $/$ day \\
\hline
\end{tabular}

\section{Model Development}

\subsection{Model 1: Roughness Deterioration} Model Considering Pavement Age

The initial analysis focused on developing a pavement roughness deterioration model without considering the traffic. The relationship between IRI and pavement age was developed using regression analysis as illustrated in equation 5, with $\mathrm{R}^{2}$ of 0.79 and standard error (SE) 0.63 for the sample size (N) of 221.

$I R I=6.86-4.66 \exp ^{-0.0006 \mathrm{Age}^{\wedge} 3.46}$.

Where, IRI is the IRI value at the considered time after recent overlay in $\mathrm{m} / \mathrm{km}$ and Age is the pavement age in years.



Figure 2 - Pavement Roughness Deterioration with Age 
As shown in Figure 2, it is observed that the pavement age has a non-linear relationship with pavement roughness. Moreover, it shows that, at the early stage of pavement life (within the first 5 years), pavement roughness is not increasing significantly (at $0.14 \mathrm{~m} / \mathrm{km}$ IRI per annum on average) and remains under the IRI value of $3 \mathrm{~m} / \mathrm{km}$. Then, IRI increases significantly until year 12 and steadies at IRI of $7 \mathrm{~m} / \mathrm{km}$ (at $0.54 \mathrm{~m} / \mathrm{km}$ IRI per annum, on average). There is no further increase of IRI after that based on the data available for the study area. One reason could be the periodic maintenance works such as thin AC overlay on national roads would have been carried out on such road sections.

\subsection{Model 2: Roughness Deterioration} Model Incorporating Traffic Flow

The analysis is continued for the different ADT ranges by dividing into three categories as:

Low (ADT<20,000 veh/day); Moderate(20,000 veh/day<ADT<65,000 veh/day); and High (ADT $>65,000$ veh/day) [45]. Most of the class A roads include in the high traffic category and most of the class B roads in the moderate traffic category. For the Low ADT category, only one road section was found since highways in the Western Province have relatively higher traffic volumes. Therefore, the models for moderate and high ADT categories were further analyzed in this study.

Equations 6 \& 7 show the relationship between pavement roughness and pavement age concerning the variation in traffic level. The deterioration models are statistically significant with $\mathrm{R}^{2}$ of 0.85 and 0.77 for moderate and high traffic categories, respectively.

$I R I=2.0918+0.2909$ Age

$I R I=1.679 e^{0.133 \mathrm{Age}}$

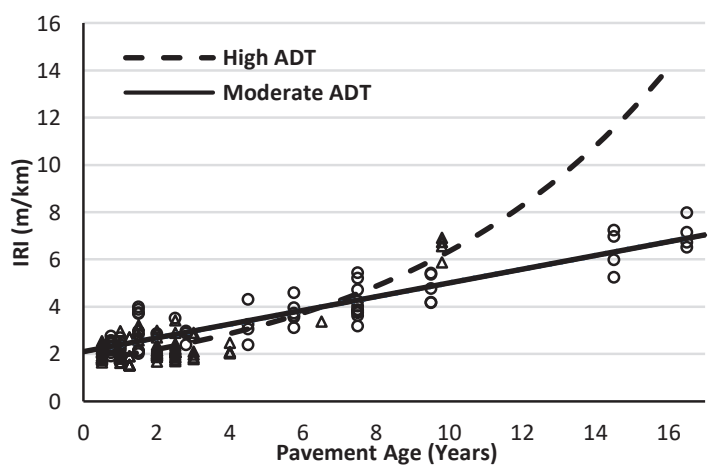

Figure 3 - Pavement Roughness Deterioration under Moderate and High Traffic
Figure 3 illustrates that increasing traffic volume accelerates the pavement deterioration rate. Further, in moderate traffic condition, deterioration pattern is linear, while in high traffic condition when pavement tends to be older, the deterioration rate increases drastically.

\subsection{Multiple Regression Model for Roughness Progression}

For this analysis, roughness and ADT were used as the independent variables. IRI progression is predicted as a function of ADT and pavement age as structured in equation 8 .

$I R I_{t}=I R I_{0}+f(A g e, A D T)$

Where, $I R I_{t}$ is the $I R I$ value at time ' $t$ ' after construction, $I R I_{0}$ is the initial IRI value at time zero and $A D T$ is the annual daily traffic volume in veh/day.

$I R I_{0}$ is determined by selecting the roads in which pavement age is lesser than one year. The descriptive statistic results of $I R I_{0}$ are shown in Table 5.

Table 5 - Descriptive Statistics of $I R I_{0}$

\begin{tabular}{|c|c|}
\hline Description & IRIValue $\mathbf{( m / k m )}$ \\
\hline $5 \%$ Value & 1.74 \\
\hline Average & 2.15 \\
\hline 95\% Value & 2.95 \\
\hline Standard Deviation & 0.35 \\
\hline Number of Segments & 79 \\
\hline
\end{tabular}

Therefore, $I R I_{0}$ is considered as the mean value of IRI $2.15 \mathrm{~m} / \mathrm{km}$ in the further analysis. Then, the non-linear multiple regression analysis is conducted by minimizing the residual error of the model. The prediction model is shown in equation 9, which is statistically significant with an $\mathrm{R}^{2}$ of 0.83 . The accuracy was checked by using scatter plots of observed IRI with the predicted IRI by the model shown in Figure 4.

$I R I_{t}=2.15+0.0003 \mathrm{Age}^{1.7343}\left(1+A D T^{0.5075}\right)$

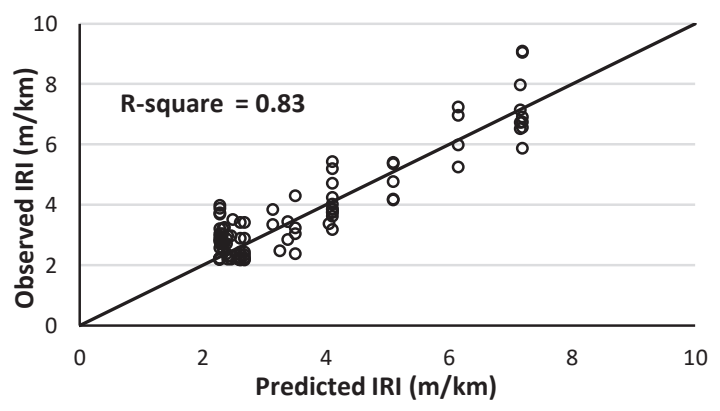

Figure 4 - Scatter Plot of IRI Values Predicted by the Model and Observed Values 


\section{Comprehensive Overview of the Developed Models}

The developed pavement deterioration curves have $\mathrm{R}^{2}$ greater than 0.75 , that indicate the models are statistically significant. The proposed model is also similar to the existing roughness deterioration models developed in other countries, as shown in Figure 5.

As shown in Figure 5, the initial IRI proposed by the study can be accepted since initial IRI of all the other models are around $2 \mathrm{~m} / \mathrm{km}$. In the proposed model, IRI progression trend is similar to most of the existing models which are showing non-linear behaviour. In the first 6 years, IRI progression rate of all models is similar to the developed one which is 0.14 $\mathrm{m} / \mathrm{km}$ IRI per annum on average. Then, deterioration rate is accelerated such as in India (0.55 m/km/year) [46], and Austroads (Australia) $(0.38 \mathrm{~m} / \mathrm{km} /$ year) [47] compared to $0.54 \mathrm{~m} / \mathrm{km}$ in the proposed model.



Figure 5 - Comparative Progression of IRI Values Predicted by Models with Time

Moreover, at the pavement age of 16 years, IRI is a stable value around $7-8 \mathrm{~m} / \mathrm{km}$ in most of the models including the proposed one. For further clarification, Table 6 illustrates the time taken by different models to reach different thresholds. The threshold values are selected as per the local classification by RDA [41]. The overall results show that the proposed model has similar IRI progression trend with India and Austroads which have relatively same climate and traffic characteristic as Sri Lanka.
IRI progression is accelerated with increasing $A D T$ values as per the developed multiple regression model (equation 7) in this study. To evaluate the deterioration trend in each $A D T$ category, IRI progression is plotted against pavement age and illustrated in Figure 6. The figure shows that the IRI progression trend is similar to what is observed in Figure 3. Hence, there is sufficient evidence that the multiple regression model follows the real trends observed by the field data. When ADT is changed from 20,000 veh/day to 65,000 veh/day the increase of the deterioration rate is $81.4 \%$ (increased from IRI of $0.38 \mathrm{~m} / \mathrm{km}$ to 0.69 $\mathrm{m} / \mathrm{km}$ per annum on average), which concludes that traffic flow volume is significant in IRI progression modelling.

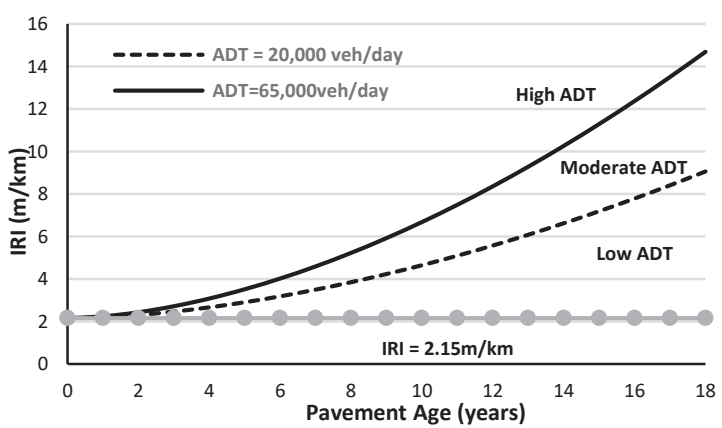

Figure 6 - IRI Progression Trend in Different ADT Categories

\section{Evaluation of the Influence of Distress Types on the HDM-4 Roughness Deterioration Model}

HDM-4 software is often used in Sri Lanka as a pavement management system for rehabilitation and maintenance planning work. Typically, the default deterioration model is used due to the lack of calibration data and related analysis that is required. The results of this study can be used to calibrate the default model and find the relationship between distresses in the IRI progression. The IRI increment is modelled in HDM-4 following the function shown in equation 10 [47].

$\Delta R I=K_{g p}+\Delta R I_{s}+\Delta R I_{c}+\Delta R I_{r}+\Delta R I_{t}+\Delta R I_{e . .}$

Table 6 - Comparison of IRI Evolution According to Different Performance Models

\begin{tabular}{|c|c|c|c|c|c|c|}
\hline \multirow{2}{*}{$\begin{array}{c}\text { Threshold } \\
(\mathbf{m} / \mathbf{k m})\end{array}$} & \multicolumn{6}{|c|}{ Year for IRI Reaching to Threshold According to Model } \\
\cline { 2 - 7 } & Proposed & Indian [46] & Austroads [47] & Hungarian [46] & Brazil [30] & Brazil [31] \\
\hline 3 & 5 & 5 & 4 & 7 & 7 & 8 \\
\hline 5.5 & 9 & 10 & 11 & 14 & 15 & 15 \\
\hline 7 & 12 & 12 & 15 & 17 & 16 & 18 \\
\hline 10 & - & 15 & $>20$ & $>20$ & 17 & $>20$ \\
\hline
\end{tabular}


Where, $K_{g p}$ is the calibration factor of general surface roughness development, $\Delta R I$ is the gradual increase of pavement surface roughness, $\Delta R I_{s}$ is the structural pavement deterioration, $\Delta R I_{c}$ is the deterioration due to cracking, $\Delta R I_{r}$ is the deterioration due to rutting, $\Delta R I_{t}$ is the deterioration due to potholes and $\Delta R I_{e}$ is the deterioration due to climate effects.

The data available for pothole, cracking and ravelling while the effect of those distresses due to roughness is established by using equations 11 to 13 in HDM-4 [47]. Due to the nonexistence of the calibration equation for ravelling, it is modelled the same as for the cracking.

$$
\begin{aligned}
& \Delta R I_{e}=K_{g m} \cdot m \cdot R I_{a} \\
& \Delta R I_{c}=K_{g c} \cdot a_{0} \cdot \Delta A C R A \\
& \Delta R I_{p}=K_{g p} \cdot a_{0} \cdot\left(a_{1}-F M\right) \cdot\left(N P T_{b u}\right)^{a 2} .
\end{aligned}
$$

Where, $m$ is the temperature and precipitation adjustment factor ( 0.02 for Sri Lanka), $R I_{a}$ is the $I R I$ at start of the analysis, $\triangle A C R A$ is the incremental changing area percentage (\%) during analysis year, $F M$ is the freedom to manoeuvre (set as zero), $N P T_{b u}$ is the number of potholes in a kilometer, $a_{0}, a_{1}, a_{2}$ are constants $0.0066,2.002,1.5$, and $K_{g m,}, K_{g c,} K_{g p}$ are the calibration factors for environmental, cracking and potholes, respectively.

The regression analysis is conducted to find the relationship between IRI and distresses as illustrated in Table 7.

Table 7 - The Best Representative Functions of Distress vs Age

\begin{tabular}{|c|c|c|}
\hline $\begin{array}{c}\text { Distress } \\
\text { Type }\end{array}$ & $\begin{array}{c}\text { Regression } \\
\text { Function }\end{array}$ & $\begin{array}{c}\text { Goodness } \\
\text { of Fit }\end{array}$ \\
\hline Ravelling & $\begin{array}{c}\text { Ravelling } \\
\text { Area } \%=23 /(1+481.1 \\
\left.6 \mathrm{e}^{-1.06 A g e}\right)\end{array}$ & $\begin{array}{c}\mathrm{R}^{2}=0.91, \\
\mathrm{~N}=15\end{array}$ \\
\hline Pothole & $\mathrm{NPT}_{b u}=14.35 \mathrm{e}^{-2.99 / A g e}$ & $\begin{array}{c}\mathrm{R}^{2}=0.76, \\
\mathrm{~N}=10\end{array}$ \\
\hline Cracking & $\begin{array}{c}\text { Crack Area } \%= \\
0.1018 \text { Age }\end{array}$ & $\begin{array}{c}\mathrm{R}^{2}=0.5566 \\
\mathrm{~N}=17\end{array}$ \\
\hline
\end{tabular}

The distresses are categorized into three categories such as surface disintegration (ravelling, potholes, polishing), cracking (longitudinal cracks, transverse cracks, alligator cracks, block cracks) and surface deformation (rutting, distortion) [26]. The influence of different distress categories to IRI progression is plotted, then compared with the developed model in the study as shown in Figure 7. It was found that surface disintegration is the dominant component of the pavement deterioration. Moreover, existing ravelling, potholes and cracking will increase the rate of deterioration significantly, especially in the older pavements. From this, the marginal contribution $(\Delta R I)$ can be estimated for each distress type at each stage of the pavement's life cycle.

As an example, at age 10, the IRI value is 6.03 $\mathrm{m} / \mathrm{km}$ and $\Delta R I$ is $3.83 \mathrm{~m} / \mathrm{km}$. At that stage, $I R I$ progression is dominated by surface disintegration which influences $73.6 \%$ of total IRI progression. Moreover, cracking contributes to $22.2 \%$ of it and the remaining amount is due to surface deformation. The marginal contribution is varying with the stage, while at early stages, cracking is predominant as shown in Figure 7.

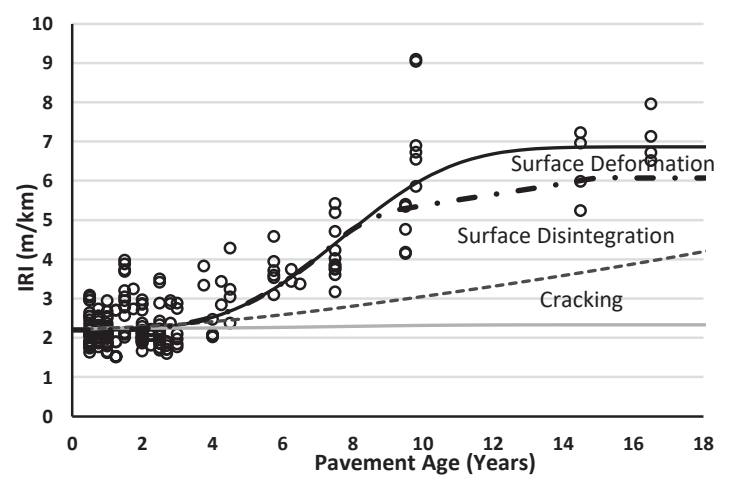

Figure 7 - Impact of Different Distress Component on Roughness Progression

\section{Conclusion}

In this study, 31 road sections were selected, and detailed pavement functional condition evaluations (roughness and distresses) were conducted. Empirical models were developed between IRI and pavement age and traffic volume. As expected, traffic flow volume also plays a significant role in IRI progression, the percentage increase in deterioration rate is $89 \%$ when traffic volume increases for medium to high category. Further, the multiple regression model has shown a similar value of $81.4 \%$, when ADT change from 20,000 veh/day to 65,000 veh/day.

The developed models were found to be comparable with existing models in other countries as shown in Figure 5. The average pavement roughness progression (0.14 
$\mathrm{m} / \mathrm{km} /$ year in the first 5 years and 0.54 $\mathrm{m} / \mathrm{km} /$ year up to year 12) found in this study is useful for predicting the roughness progression of the national highways, under similar conditions. Irrespective of the traffic volumes, the general IRI model shown in Figure 2 can be used in the condition deterioration prediction. Further, all models proven that the initial $I R I$ about $2 \mathrm{~m} / \mathrm{km}$ as the lower limit for national roads.

Moreover, the influence of different distress components to roughness progression is modelled by using HDM-4 software, road deterioration and work effects (RDWE) model. Influence of pothole, cracking, ravelling and climate effect (as the environmental component) on the deterioration is evaluated and surface disintegration (pothole and ravelling) is found to be the dominant category. The results indicate that the roughness deterioration model provides accurate results and can be used as in puts for planning level decision making, especially at the national level.

\section{Acknowledgment}

Data collection was carried out with the support given by the Road Development Authority, Sri Lanka.

\section{References}

1. http://www.rda.gov.lk/,Visited, 2020/04/27.

2. Ministry of Finance, Sri Lanka, "Annual Report", Ministry of Finance, Colombo, 2018.

3. Department of National Planning, Ministry of National Policies and Economic Affairs, Sri Lanka, "Public Invest Programme", Ministry of National Policies and Economic Affairs, Colombo, 2017.

4. Federal Highway Administration (FHWA), "Pavement Smoothness Technologies", http://www.fhwa.dot.gov/teams/pavement/pa ve_5psm.cfm,/Visited 2020/04/30.

5. Mubaraki, M., "Highway Subsurface Assessment using Pavement Surface Distress and Roughness Data", International Journal of Pavement Research and Technology, Vol. 9, 2016, pp. 393-402.

6. Ranawaka, S. \& Pasindu, H. R., "A Case Study on Economic Cost Increment in Urban Highway Work Zones", in11th Asia Pacific Conference on Transport and the Environment, Malang, Indonesia, October, 2018.
7. Gaspar, L., Veeraragavan, A., \& Bako, A., "Comparison of Road Pavement Performance Modelling of India and Hungry", Act a Technical Jaurinensis, Vol. 2, No. 1, 2009, pp. 35-56.

8. Martin, T., \& Choummanivong, L., "Effectiveness of Maintenance Activities on Pavement Condition", Austroads Ltd., 2018.

9. Al-Suleiman, T. I., \& Shiyab, A. M., "Prediction of Pavement Remaining Service Life Using Roughness Data-Case Study in Dubai", International Journal of Pavement Engineering, Vol. 4, No. 2, 2003, pp. 121-129.

10. DOT, “Freight Future-Victorian Freight Network Strategy for a More Prosperous and Liveable Victoria", Department of Transport, Victoria, Australia, 2008.

11. Graves, S. J., Rochowiak, D. \& Anderson, M. D., "Mining and Analysis of Traffic Safety and Roadway Condition Data", University Transportation Centre for Alabama, 2005.

12. Alaswadko, N., Hassan, R., \& Evans, R., "Effect of Traffic and Environmental Factors on Roughness Progression Rate of Sealed Low Volume Arterials,", Swinburne University of Technology, Victoria, Australia, 2014.

13. Haifang, W., "Design Factors Affecting the Initial Roughness of Asphalt Pavements", International Journal of Pavement Research and Technology, Vol. 4, No. 5, 2011, pp. 268-273.

14. Perera, R. W., \& Kohn, S. D., "Achieving a High Level of Smoothness in Concrete Pavements Without Sacrificing Long-Term Performance, Final report to Federal Highway Administration", FHWA-HRT-05-069, McLean, VA, USA, 2005.

15. Radović, N., Jokanović, I., Matić, B., \& Šešlija, M., "A Measurement of Roughness as Indicator of Road Network Condition - Case Study Serbia", Technical Gazette 23, Vol. 3, 2016, pp. 881-884.

16.Owolabi, A. O., Sadiq, O. M., \& Abiola, O. S., "Development of Performance Models for a Typical Flexible Road Pavement in Nigeria", International Journal of Traffic and Transportation Engineering, Vol. 2, No. 3, 2012, pp. 178-184.

17. Jameson, G., "Guide to Pavement Technology: Part 2: Pavement Structural Design", 2012.

18. Mann, A., "The Identification of Road Sections in Victoria Displaying Roughness Caused by Expansive Soils", Swinburne University of Technology, 2003.

19. Sayers, M. W., \& Karamihas, S. M., The Little Book of Profiling, University of Michigan, 1998. 
20. Sayers, M. W., “Two Quarter-Car Models for Defining Road Roughness: IRI and HRI", Transportation Research Record1215, 1989, pp. 165172.

21. Lytton, R. L., “Concept of Pavement Performance Prediction and Modelling", in Second North American Conference in Managing Pavements, Toronto, Ontario, Canada, Vol. 2,1987, pp. 3-19.

22. George, K. P., Rajagopal, A. S. \& Lim, L. K., "Models for Predicting Pavement Deterioration", Transportation Research Record1215, 1987, pp. 3039.

23. Carnahan, J. V., Davis, W. J., Shahin, M. Y., Keene, P. L., \& Wu, M. I., "Optimal Maintenance Decisions for Pavement Management", Journal of Transportation Engineering, ASCE, Vol. 113, No. 5, 1987, pp. 554-572.

24. George, K. P., “MDOT Pavement Management System," FWHA/MS-DOT-RD-00-119, 2000.

25. Prozzi, A. \& Madnat, S. M., “Development of Pavement Performance Models by Combining Experimental and Field Data", Journal of Infrastructure System, Vol. 10, no. 1, 2014, pp. 9-22.

26. Prozzi, A. \& Madnat, S. M., "EmpiricalMechanistic Model for Estimating Pavement Roughness", in 82nd Annual Meeting of Transport Research Board, Washington DC, 2003.

27. Li, N., Hass, R., \& Xie, W. C.,"Development of a New Asphalt Pavement Performance Prediction Model",Canadian Journal of Civil Engineering, Vol. 24, no. 4, 2011, pp. 547-559.1

28. Sayers, W. M., Karamihas, M. S., “Basic Information about Measuring and Interpreting Road Profiles",University of Michigan, 1998.

29. Múčka, P., "International Roughness Index Specifications around the World", Road Materials and Pavement Design, Vol. 18, No. 4, 2017, pp. 929965.

30. Paterson, W. D. O., "Road Deterioration and Maintenance Effects: Models for Planning and Management", World Bank Publications, Washington, D.C. 1987.

31. Soncim, S. P., Oliveira, I. C. S., Santos, F. B., \& Oliveira, C. A. C., "Development of Probabilistic Models for Predicting Roughness in Asphalt Pavement", Road Materials and Pavement Design, 2017.

32. ARA, Inc., ERES Division, "Guide for Mechanistic-Empirical Design of New and Rehabilitated Pavement Structures", National Cooperative Highway Research Program (NCHRP), Transportation Research Board, 2004.
33. Albuquerque, F. S., \& Núñez, W. C., "Development of Roughness Prediction Models for Low-Volume Road Networks in Northeast Brazi", Transportation Research Record2205, 2011, pp. 198-205.

34. Li, N., Xie, W. C., \& Haas, R., "Reliability-based Processing of Markov Chains for Modeling Pavement Network Deterioration", Transportation Research Record1524, 1996, pp. 203-213.

35. Austroads, "Guide to Asset Management Part 5B: Roughness (Report No. AGAM05B-07)," Austroads Publication, 2007.

36. Czech Office for Standards, Metrology and Testing Measurement and Evaluation of Road Surface Unevenness, 2015.

37. Mogilny, K. V., Lushnikov, N. A., \& Krasikov, O. A.," International Roughness Index and its use in Countries of the Customs Union", 2013, pp. 92110.

38. Norwegian Public Roads Administration., Road Construction (Handbook N200), 2014.

39. Department of Public Works and Highways," Adoption of International Roughness Index Values for all National Primary Roads", Department Order No. 47. Manila, Philippine, 2015.

40. New Zealand Transport Agency," State Highway National Pavement Condition Report", Wellington, 2009.

41. Road Development Authority, "National Road Master Plan 2018-2027", 2017.

42. Gnanasekaran, G., " Quality Control Aspect of Asphalt concrete Surface Regularity," University of Moratuwa, Moratuwa, 2010.

43. http://arrbgroup.net/products/hawkeye-2000series//,Visited, 2020/04/27.

44. https://romdas.com/romdasbumpintegrator.html/, Visited, 2020/04/27.

45. Gaspar, L., Veeraragavan, A., \& Bako, A., "Comparison of Road Pavement Performance Modelling of India and Hungry," Acta TechnicaJaurinensis, Vol. 2, No. 1, 2009, pp. 35-56.

46. Martin, T., \& Choummanivong, L., “Effectiveness of Maintenance Activities on Pavement Condition," Austroads Ltd., 2018.

47. Morosuik, G. \& Riley, M., "Modelling Road Deterioration and Works Effects in HDM-4," PIARC World Road Association, Paris, 2004. 